\title{
The Posthuman Poetics of Instagram Poetry
}

\author{
Jeneen Naji \\ Dept. of Media Studies \\ National University of Ireland Maynooth \\ jeneen.naji@mu.ie
}

\begin{abstract}
Technological developments and constraints have always influenced and shaped human cultural artefacts such as poetry, stories and music (Emerson, 2014: ix) and the same is true of the vast variations of the digital apparatus. As a result, the forward momentum of the contemporary explosion of online cultural content has far reaching implications on human subjectivities in cyberspace (Hayles, 1999). The construction and analysis of new digital literary artefacts with regards their impact on literary expression and reception is a timely venture that can help us begin to understand, anticipate, and drive the changing shape of human culture. For example, Instagram poetry, a type of digital poetry is, as the name implies, poetry that is produced for distribution through the social media platform Instagram and most usually incorporates creative typography with bite size verses. Instagram poets such as @atticuspoetry (517k followers) @christopherpoindexter (325k followers) and @rupikaur_(1.8 million followers) have in fact proven to be so popular that their work also appears as best-selling print books. Instagram poetry can demonstrate the cultural impact of a posthuman cyborgian fluidity of borders and forms in that we essentially find ourselves left with anthropophagic texts - cannibalistic texts that remix, reuse and re-appropriate content. This paper will examine existing and contemporary examples towards the goal of a deeper understanding of Instagram poetry as a posthuman literary artefact.
\end{abstract}

This paper has emanated from research conducted with the financial support of Science Foundation Ireland (SFI) under Grant Number 15/IA/3090.

Electronic Literature. Digital Poetry. Posthuman. Cyborg. Transcreation. Anthropophagy. Literary Artefacts. Instagram. Hermeneusis.

\section{INTRODUCTION}

Technological developments and constraints have always influenced and shaped human cultural artefacts such as poetry, stories and music (Emerson, 2014: ix) and the same is true of the vast variations of the digital apparatus. As a result, the forward momentum of the contemporary explosion of online cultural content has far reaching implications on human subjectivities in cyberspace (Hayles, 1999). Much of what we encounter in our daily lives has been digitised and we are in what Hayles (1999) terms the "posthuman" era as we all are increasingly continually connected and hence defined by digital influences both in media and elsewhere. We can no longer talk of the machine impersonally when we are in fact connected to and part of it, directing the flow of digital data. Instagram poetry is a networked art practice that is anthropophagic in nature in the sense that it is continuously remixing and reusing content. Fallon
(2014: 57-58) highlights how the Instagram app invites users to manipulate images as a step before posting and that this ubiquity of image making on digital devices means that all authors are readers and readers are authors in a collective and networked social media environment. Further analysis of this new creative environment with regards its impact on literary expression and reception is a timely venture that can help us begin to understand, anticipate, and drive the changing shape of human culture. New genres such as electronic literature and digital art have emerged that encompass digital cultural artefacts that require a digital apparatus to both consume and produce the text or artwork. Digital poetry is a subgenre of electronic literature and Instagram poetry, a type of digital poetry is, as the name implies, poetry that is produced for distribution through the social media platform Instagram and most usually incorporates creative typography with bite size 
verses. Many Instagram poets such as @atticuspoetry (517k followers) @christopherpoindexter (325k followers) and @rupikaur_(1.8 million followers) have in fact proven to be so popular that their work also appears as best-selling print books. This paper examines specific examples of Instagram poetry in order to identify their unique characteristics and affordances.

\section{METHODOLOGY}

My methodology for this investigation was simple, on April 42018 I searched for the hashtag \#instagrampoetry and a result of 84,504 posts appeared with 9 top posts.

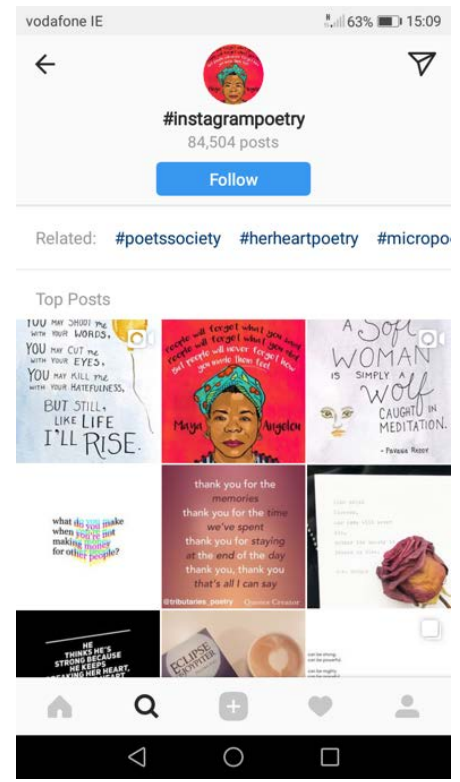

Figure 1: This is a screenshot of my search for \#instagrampoetry on April 4, 2018.

There are many other related and relevant hashtags for Instagram poetry such as \#poetryofinstagram $(860,191$ posts), \#digitalpoet (2,606 posts), \#poetrygram (341,535 posts), \#poetryisnotdead (1,844,782 posts), and \#micropoetry $(266,501$ posts). You can see the screenshots for these searches in the images below. I deemed a search methodology such as this to be the more rigorous option (as opposed to analysing specific Instagram poetry accounts with the most followers) as it lists the amount of posts with that hashtag which is a more reliable indicator of popularity given that followers can be bought.

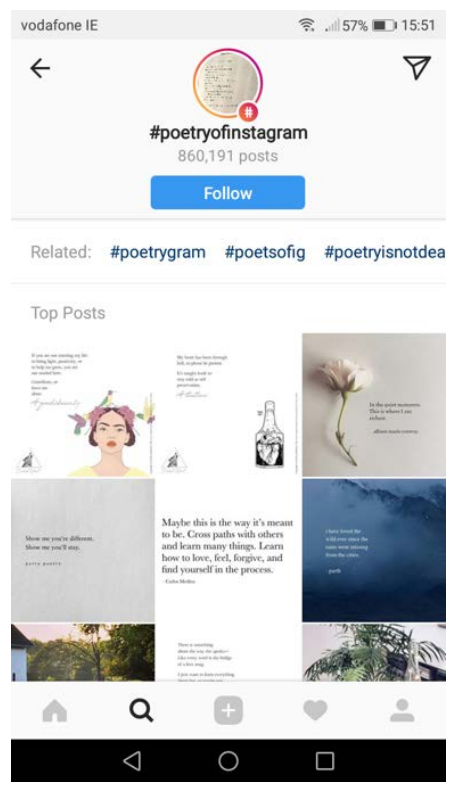

Figure 2: This is a screenshot of my search for \#poetryofinstagram on April 4, 2018.

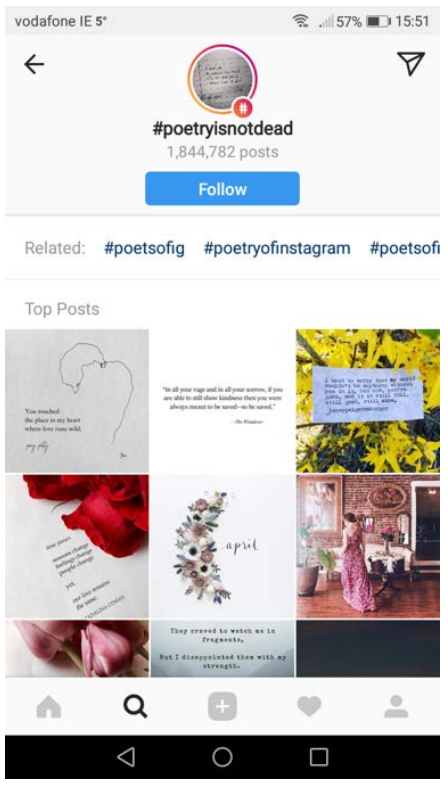

Figure 3: This is a screenshot of my search for \#poetryisnotdead on April 4, 2018. 


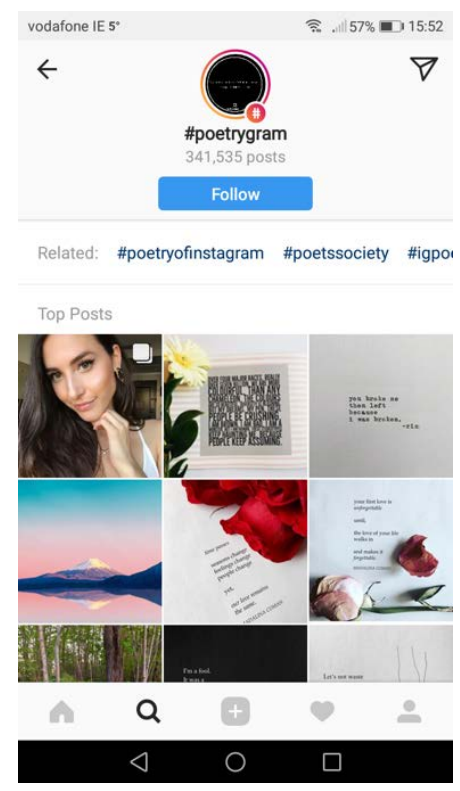

Figure 4: This is a screenshot of my search for \#poetrygram on April 4, 2018.

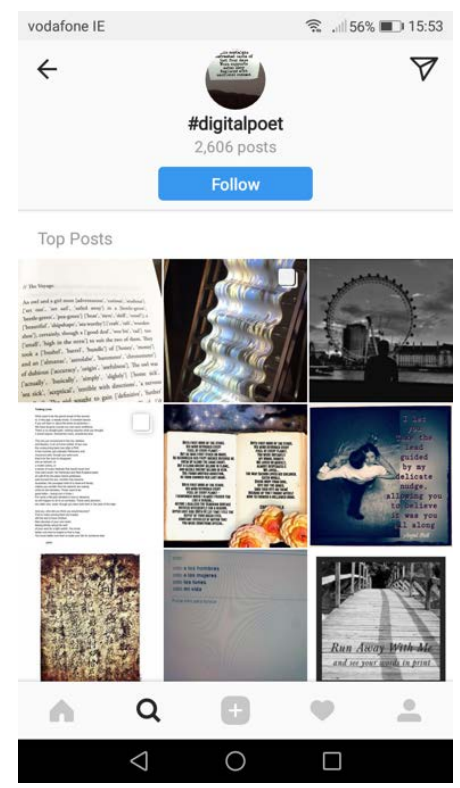

Figure 5: This is a screenshot of my search for \#digitalpoet on April 4, 2018.

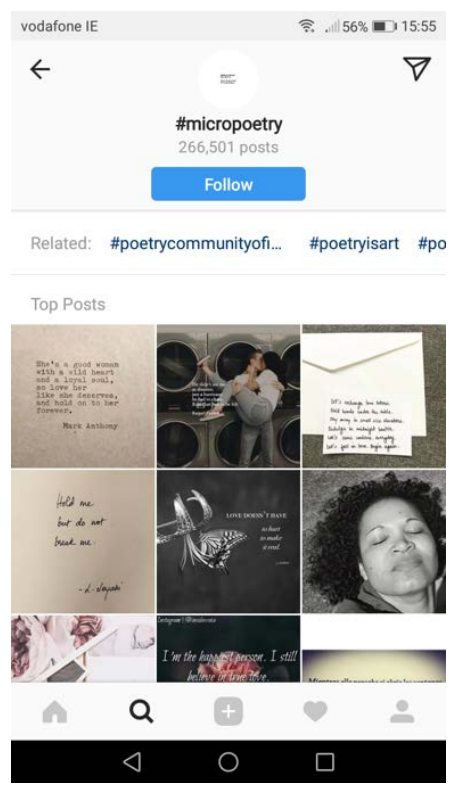

Figure 6: This is a screenshot of my search for \#micropoetry on April 4, 2018.

For practicality and achievability's sake I focused on the very literal hashtag \#instagrampoetry and I clicked through each of the top 9 posts and took a screenshot of each post.

For the purposes of this paper I will focus on the first three posts (Figures 7, 8, and 9 below) which are all from Makerswomen an instagram account that describes itself as a "feminist media brand for changeMAKERS, newsMAKERS, historyMAKERS, and troubleMAKERS. Join our mission to BREAK. EVERY. CEILING. " (Makerswomen).

The first two Instagram posts contain Maya Angelou quotes and this was to do with April 4 being her birthday demonstrating the sensitivity of Instagram poetry to contemporary socio-cultural currents. The first image is created by a New York based illustrator called Nathalie Gonzalez. The second and third posts are illustrated by @kimothjoy, a "Denver-based artist who creates illustrations made with joy to spark social change. She partners with people and organizations on social-awareness campaigns to inspire thought and action" (Kimothjoy). The third Instagram post quotes Los Angeles based writer Pavana Reddy, who is herself an active Instagram poet with $56.4 \mathrm{k}$ followers and a poetry book available on amazon. The quote is placed on a watercolour painting type style background with an animation of a woman's face turning into a wolf's head. The first post (Figure 7) with the Maya Angelou quote also contains audio of Maya Angelou speaking the same words quoted "You may shoot me with your words, You may cut me with your eyes, You may kill me with your hatefulness, But still, like air, I'll rise." This is the 6th verse from Maya Angelou's poem Still I Rise. 


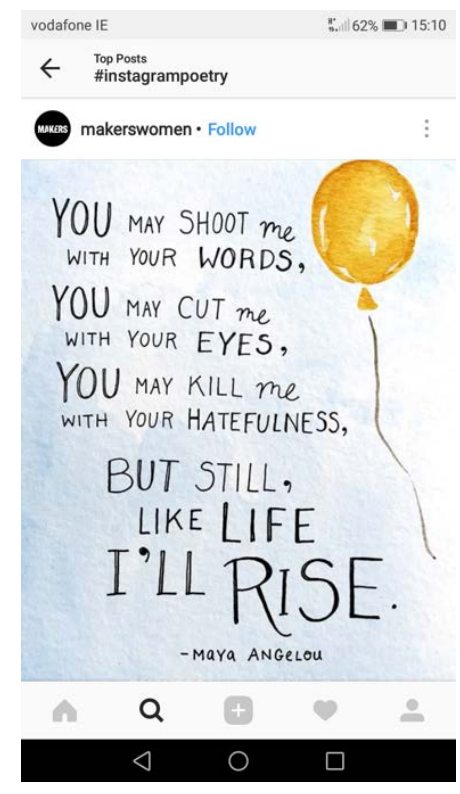

Figure 7: The first Instagram screenshot from @makerswomen

When I conducted another search for \#instagrampoetry on April 12th, 2018 these three posts still appeared in the top 9 posts. The hashtag \#nationalpoetrymonth indicates that these posts were made for April 2018 National Poetry month in the USA. All three have a strong collaborative and feminist maker networking aspect to them most usually iterated in the hashtags.

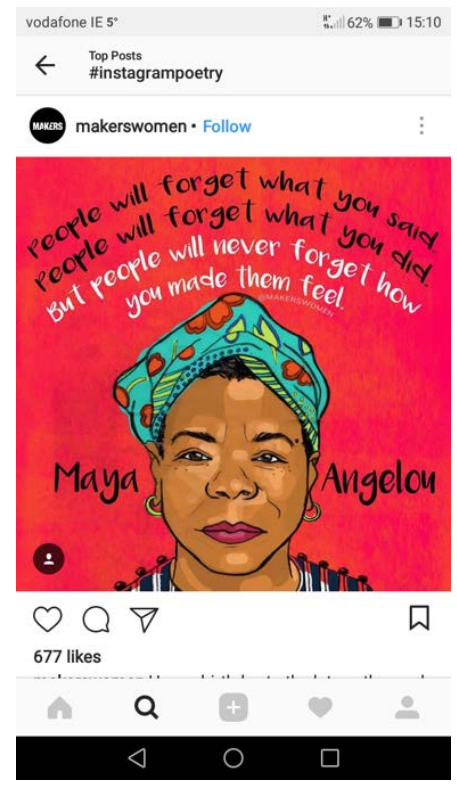

Figure 8: The second instagram screenshot from @makerswomen

\section{ANALYSIS}

Leonardo Flores (2018) suggests that the contemporary digital landscape of sharing, copying, pasting, linking and remixing of content to massive audiences and communities such as can be found in Instagram poetry has spawned a new category of electronic literature, what he refers to as third generation literature. According to Flores (2018), third generation literature works in spaces with massive audiences. Instagram poetry is an example of third generation electronic literature that can demonstrate massive audiences and remixed content, we can see this taking place in these three posts that are recirculating content from Maya Angelou and Pavana Reddy poetry along with original illustrations from contemporary female artists. Care is taken in the hashtags however to always cite or connect to the content creators thereby highlighting the networked nature of this cultural form.

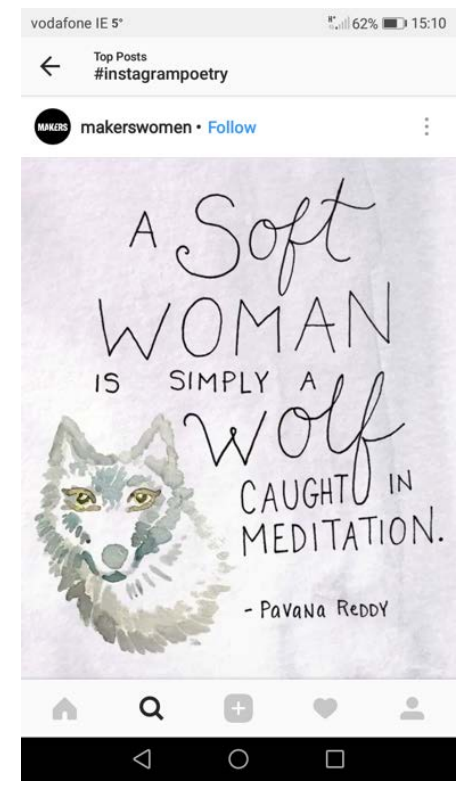

Figure 9: The third instagram screenshot from @makerswomen

In his book Networked Art (1997) Craig Shaper talks about a historical lineage of sociopoetic works that arise out of avant-garde art and visual poetry (152) practice of artists. These works he suggests cannot be read the way one reads a phonetic poem but rather as works about our current cultural situations (152). In describing a new path for art and poetry in the 1990s Shaper suggests that "much of the work depends on the situation of its distribution and production; hence the production often involves the use of found objects, texts, and images, and the distribution depends on participants' setting up various chain-letter- like links. In that sense, the work will resemble neither the "readerly" classic texts nor the "writerly" modernist texts. Instead, the interpretation of these works depends on reference to a network of participants. The use of pseudonyms in this context functions as a crucial component in socio- poetic work on authorship, collective action, and creativity". In the Instagram poetry examples, we have looked at we can see at play the use of found 
objects in the Instagram account makerswomen which recirculates existing content and commissions original art and designs. Instagram is a novel and contemporary form of networked art that reflects and comments on contemporary cultural situations as all art should. The innovation and fluidity of these works is underecognised as much criticism of Instagram poetry often describes it as immature and shallow. Is the fact that a large proportion of very popular Instagram poets and content female oriented a factor in this criticism? 8 out of the 9 top Instagram posts that I listed are from women or female collaborations.

\subsection{Criticism of Instagram Poetry}

In the Jan - Feb 2018 edition of the PN Review Rebecca Watts wrote The Cult of the Noble Amateur in which she describes "the rise of a cohort of young female poets who are currently being lauded by the poetic establishment for their 'honesty' and 'accessibility' - buzzwords for the open denigration of intellectual engagement and rejection of craft that characterises their work". In her article, she quotes work from Instagram poet Rupi Kaur's 2015 title Milk and Honey published by Andrews McMeel publishing.

In the same article, Rebecca Watts (2018) states that "of all the literary forms, we might have predicted that poetry had the best chance of escaping social media's dumbing effect; its project, after all, has typically been to rid language of cliché. Yet in the redefinition of poetry as 'shortform communication' the floodgates have been opened. The reader is dead: long live consumerdriven content and the 'instant gratification' this affords.

Carl Wilson suggests that Instagram poetry could be the birth of young adult poetry like a midway point between children's poetry and adult poetry (BBC Radio 4: 2018). A Guardian article written in February 2016 by Michelle Dean entitled Instagram poets society: selfie age gives new life and following into poetry rebuffs David Denby who wrote a New Yorker article concerned that younger generations were not reading the "Classics" of great literature. Dean quotes from the comments section of popular Instagram poet @Atticus in which his readers list their top ten poets and "classic" names such as "Orwell, Flannery O'Connor, Sylvia Plath, Khalil Gibran and Maya Angelou" appear. Dean (2016) also points out that Instagram poets are often also Tumblr and Pinterest poets, these are all social media channels that amass huge audiences of reading communities that share, remix and recirculate content continuously.
It is this continuous recirculation remixing and sharing that is particularly interesting about Instagram poetry and the way the form invites participation in a manner similar to Delwiche and Henderson's (2012) theories regarding participatory culture and discussion communities. So, for example many users will requote Atticus poetry while sharing with one of their own images and include the hashtag \#atticus to reference the quote. This can provide a new dimension of meaning to a couple of lines of poetry and often personalise the experience for members of the community. To critique Instagram poetry the same way one critiques print poetry by focusing only on the words is like evaluating an elephant based on its trunk, we are missing a large part of the animal, in this case its socio-technical apparatus and networks.

\subsection{Literary Anthropophagy}

In Augusto de Campos, Digital Poetry, and the Anthropophagic Imperative, Chris Funkhouser (2007) tells of an obscure creative philosophy exemplified by Oswald de Andre's 1928 Anthropophagy Manifesto which proclaims, "I am only interested in that which is not my own". I did wonder whether referring to digital poetry as an ouroboric practice might be better suited than anthropophagic given the negative connotation of the consumption of human flesh in anthropophagy, however in these examples of Instagram poetry we can see authors primarily drawing on other sources or "eating" so to speak other texts and even genres, not their own, so in this sense it is appropriate that digital poetry can be seen as an anthropophagic practice as it not only feeds on contemporary culture but it can be seen to build on the extant traditions of early video experimentation and net art. Whilst literary anthropophagy is not a new term it can be particularly useful in an analysis of contemporary of digital culture as it can allows us to rethink the trans-medial relationship between older traditional media and newer popular digital forms (Simanowski, 2010: 159). It is this interplay and conflict between old and new poetry, books and screen that evokes the most passionate arguments and valuable analysis. The reality is of course that all cultural forms feed on each other and we as humans continue to inhabit a complex web of meanings, however this web can now be seen to be embodied explicitly in online networks and social media platforms such as Instagram. In New Directions for Digital Poetry Funkhouser (2012: 6) favours the word transcreation for an anthropophagic text, whereby texts initially presented in one state transform into others. The word itself not only highlights the cannibalizing, recycling and remixing of content that is so prevalent in contemporary digital production and consumption but it also reminds us of the 
importance of creation and creativity as opposed to the soulless reassignment of content.

The collaborative and networked nature of the examples of Instagram poetry that I have discussed in this paper can demonstrate the cultural impact of a posthuman cyborgian fluidity of borders and forms in that we essentially find ourselves left with anthropophagic texts - cannibalistic texts that remix, reuse and re-appropriate content. Collaboration is evident in the creation of each post as they are collaborations between makers and writers, further to this the hashtags and comments that appear below each post each reference other expanding networks of communities and practice online. As Hayles (2012: 13) tells us, digital texts can no longer be regarded as singular standalone objects rather they are constantly changing assemblages in which inequalities and inefficiencies in their operations drive them towards breakdown, disruption, innovation and change. The sharing economy of the internet, as it is termed, means that contemporary cultural content such as poetry cannot be separated from the communities and platforms that both form and read them.

The inclusion of text in Instagram poetry is also important to consider in what is predominantly known as a photographic image based medium. Simanowski (2010: 162) tells us that it is the materiality of text in digital media that is focused on which can often undermine its linguistic signification. We can see this at play in the examples discussed in this paper, the poetic words become part of the image, subsumed and cannibalised into a primarily visual semiotic framework. In these instances, it is the words that we traditionally identify as poetry, it is the words that differentiate these Instagram posts from others to make them identifiable as poetry and yet it is the words that get subsumed into what Kress (2003: 7) terms the logic of the image.

\section{FUTURE RESEARCH}

The transformative anthropophagic processes and networks that I have identified in this paper to be evident in Instagram poetry can contribute to expanded fields of meaning and potentially offers to scope for syntheses of "discrepant cultures and expressive histories" (Funkhouser, 2012: 231). By assimilating, remixing and repurposing existing poetic content Instagram poets can offer us access to new combinatorial potentialities of hermeneusis in a novel manner. Granted the nature of intertextuality in a traditional print sense has always allowed us to form our own links and connections through texts but this time in Instagram poetry we can see explicitly at play the formation of a new literary artefact with its own unique affordances and interactions. The depth of discussion that has arisen through a literary posthuman and anthropophagic critical examination of just three Instagram poetry posts indicates the value of future research into Instagram poetry towards the goal of a deeper understanding of Instagram poetry as a posthuman literary artefact.

\section{REFERENCES}

BBC Radio 4. (2018) The Poetry of Instagram. https://www.bbc.co.uk/programmes/b09tcb4w (retrieved 12 April 2018).

Dean, M. (2016) Instagram poets society: selfie age gives new life and following into poetry. https://www.theguardian.com/books/2018/jan/23/po etry-world-split-over-polemic-attacking-amateurwork-by-young-female-poets retrieved 12 April 2018).

Delwiche, A. and Henderson, J.J. (2012). The Participatory Cultures Handbook. Routledge: New York.

Emerson, L. (2014) Reading Writing Interfaces: From The Digital To The Bookbound. University of Minnesota Press: Minneapolis.

Fallon, Kris (2014). Streams of the Self: The Instagram Feed as Narrative Autobiography. In "Proceedings of the Interactive Narratives, New Media \& Social Engagement International Conference." Eds. Hudson Moura, Ricardo Sternberg, Regina Cunha, Cecília Queiroz, and Martin Zeilinger.

Flores, L. (2018) Lecture: Third Generation Electronic Literature. http://leonardoflores.net/blog/lecture-thirdgeneration-electronic-literature/ (retrieved 12 April 2018).

Funkhouser, C. T. (2007) Augusto de Campos, Digital Poetry, and the Anthropophagic Imperative. Ciberletras: Revista de crítica literaria y de cultura, №. $17, \quad 2007$ http://www.lehman.cuny.edu/ciberletras/v17/funkha user.htm (retrieved 12 April 2018).

Funkhouser, C. T. (2012) New Directions in Digital Poetry. Continuum: London.

Hayles, N. K. (1999) How we became Posthuman: VirtualBodies in Cybernetics, Literature, and Informatics. University of Chicago Press: Chicago.

Hayles, N. K. (2012) How We Think: Digital Media And Contemporary Technogenesis. The University of Chicago Press: Chicago.

Kaur, R. (2015) Milk and Honey. Andrews McMeel Publishing: Kansas City.

Kimothjoy. https://www.kimothyjoy.com/about (retrieved 12 April 2018). 
Kress, G. (2003). Literacy in the New Media Age. Routledge: Oxon \& New York.

Simanowski, R. (2010). Digital Anthropophagy: Refashioning Words as Image, Sound and Action. Leonardo 43(2), 159-163. The MIT Press. Retrieved August 29, 2018, from Project MUSE database.

Shaper, C. J. (1997) Networked Art. University of Minnesota Press: Minneapolis.

Watts, R. (2018) The Cult of the Noble Amateur. PN Review 239, Volume 44 Number 3, January February 2018. https://www.pnreview.co.uk/cgibin/scribe?item id=10090 (retrieved 12 April 2018).

Makerswomen.@ @makerswomen, Instagram (retrieved 12 April 2018). 